\title{
Preventing and Neutralizing the Escalation of Workplace Bullying: the Role of Conflict Management Climate
}

\author{
Kristina Vaktskjold Hamre ${ }^{1}\left(\mathbb{D} \cdot\right.$ Margrethe Ringen Fauske $^{1} \cdot$ Iselin Reknes $^{1}\left(\right.$ D $\cdot$ Morten Birkeland Nielsen $^{1,2}(\mathbb{D})$ \\ Johannes Gjerstad ${ }^{2}$ (i) . Ståle Valvatne Einarsen ${ }^{1}$ (i)
}

Accepted: 7 June 2021 / Published online: 7 July 2021

(c) The Author(s) 2021

\begin{abstract}
Workplace bullying is, by definition, a gradually escalating process, theorized to occur from psychosocial stressors when there is a lack of management intervention in escalating conflicts, and a lack of fair and robust conflict management procedures in the organization. Based on national probability survey data gathered in 2015-2016 from the official Norwegian employee-register, we investigated how a strong perceived climate for conflict management may buffer the escalation of workplace bullying over time. A total of 1197 respondents participated in the study at two measuring points. The average age at baseline was 45.20 years ( $\mathrm{SD}=9.98)$, and the sample consisted of $52.1 \%$ women and $47.9 \%$ men. Structural equation modelling in Mplus 7.4 was used to test the construct validity and the study's hypothesis. As expected, the analyses showed that a strong conflict management climate buffered the escalation of workplace bullying. Exposure to bullying behaviour at $\mathrm{T} 1$ largely explained (47\%) new and increased instances of bullying behaviour at T2, but only for those employees working in what they perceived as a weak conflict management climate. We conclude that a strong conflict management climate neutralizes the escalation and development of workplace bullying.
\end{abstract}

Keywords Harassments $\cdot$ Workplace bullying $\cdot$ Conflict $\cdot$ Climate $\cdot$ Conflict management climate

\section{Introduction}

Searching for organizational factors that may prevent and defer destructive social relationships at work, the present study investigates the hypothesis that working in a perceived

Kristina Vaktskjold Hamre

kristina.hamre@uib.no

Ståle Valvatne Einarsen

Stale.Einarsen@uib.no

Margrethe Ringen Fauske

margretheringen@gmail.com

Iselin Reknes

iselin.reknes@uib.no

Morten Birkeland Nielsen

morten.nielsen@stami.no

Johannes Gjerstad

johannes.gjerstad@uib.no

1 Department of Psychosocial Science, University of Bergen, 5015 Bergen, Norway

2 The National Institute of Occupational Health (STAMI), 0304 Oslo, Norway strong and constructive climate for conflict management will buffer further escalation of potential workplace bullying cases. Knowledge of preventive factors is important for both theoretical and applied reasons, as exposure to workplace bullying has been documented as a prevalent and detrimental stressor in contemporary working life, often taking the course of a gradually escalating process (Einarsen et al., 2020). Evidence then shows that exposure to bullying is highly related to escalating interpersonal conflicts (Ågotnes et al., 2018; Baillien et al., 2009; Hauge et al., 2007), usually in combination with a hostile social climate at work and the lack of proper leadership intervention in these conflicts (Leymann, 1996; Stouten et al., 2010). This indicates that the workplace itself should be the most suitable arena for preventions, and especially so in relation to how well interpersonal conflicts and bullying processes are handled and managed (Einarsen \& Einarsen, 2021). Hence, proper conflict management in the early stages may prevent further escalation in bullying situations (Einarsen \& Einarsen, 2021), and thereby also hampering and preventing the detrimental consequences documented to follow in the footsteps of bullying. 
Bullying behaviour consists of a variety of negative and aggressive acts, often including acts of social exclusion which may frighten, humiliate, or otherwise obstruct the target (Nielsen \& Einarsen, 2012). While such negative acts can be detrimental by themselves, it is the patterned or systematic exposure over time which constitutes the real menace (Leymann, 1990; 1996). Workplace bullying is therefore often defined as a situation in which one or several persons persistently, and over a period of time, perceive themselves as being on the receiving end of negative actions from superiors or co-workers, and where the target finds it difficult to defend himself or herself against these actions (Einarsen \& Skogstad, 1996; Olweus, 1993). Yet, bullying is by nature an escalating process (Parzefall \& Salin, 2010), where bullying gradually develops over time, often originating and escalating from a mere interpersonal conflict (Baillien et al., 2017; Notelaers et al., 2018). Hence, exposure to acts of workplace bullying may exist on a continuum from the occasional exposure to negative social acts, by some denoted as incivility, to severe exposure, and victimization characteristic of a full-blown bullying case in line with the above definition. In the quest for understanding why and how this detrimental process evolves, we should be searching for triggers of the process as well as for factors that may prevent the further development of bullying. In line with this, we will employ the term "exposure to bullying behaviours" to cover the full spectrum of bullying-related experiences investigated in the present study, as our overarching aim is to focus on preventive factors that may halt the bullying process, preferably at an early stage.

\section{The Role of Conflict Management Climate in Bullying Escalation}

In Heinz Leymann's (1996) pioneering work, he described bullying as a gradually developing process encompassing four stages. The first stage consists of a triggering critical event, which is often an interpersonal conflict. This stage can be short, and sometimes difficult to recognize and confront (Leymann, 1996), often resembling any other interpersonal conflict (see also Notelaers et al., 2018). In the second stage, the situation escalates, gradually evolving into a full-blown bullying case in line with the stricter definition of workplace bullying, involving exposure to continuous criticism, humiliation, defamation, social isolation, and in extreme cases threats of violence (Einarsen et al., 2020). The third stage is denoted "personnel-administrative measures," and it is at this stage that the bullying situation becomes an "official" case, which further should lead to proper management intervention. If the intervention fails, comes too late, or does not come at all, even more severe outcomes may be evident, entering the last stage of severe trauma and a risk of exclusion from the workplace, or even working life altogether for the one targeted (see also Berthelsen et al., 2011; Glambek et al., 2014).

If leaders avoid taking responsibility and intervening in this process, there is a high risk for further escalation and further detrimental outcomes (Ågotnes et al., 2018; Baillien et al., 2009; Leymann, 1996). From the theoretical description of the process by Leymann (1996), proper conflict management intervention by management in early stages either by personal initiative or by established procedures, should therefore stop, or at least halt, further escalation. In a prospective study with a representative sample of Norwegian employees, Ågotnes and colleagues (2018) showed that interpersonal conflicts at baseline was related to becoming a victim of bullying 2 years later, yet only among employees reporting to work for a laissez-faire leader. Törnroos and colleagues (2020) showed that how employees perceive conflicts are managed in ones working environment, moderate the prospective relationship between exposure to bullying, and subsequent development of depressive symptoms and sleep problems. In the present study, we theorize that a strong and sound climate for conflict management is an important characteristic of an organisation that may neutralize the further development of bullying. In such a climate, conflicting matters are perceived to be solved early on, which will defer and halt the further escalation of workplace bullying, and actual cases will be handled firmly and constructively in early phases (e.g., Keashly at al., 2020; Leymann, 1996). This theoretical notion is partly supported by a recent crosssectional multilevel study which showed that a strong conflict management climate at team level buffered the relationship between having high job demands (e.g., role conflict) as risk factors, and the reporting of exposure to bullying behaviours associated with high job demands (Zahlquist et al., 2019), as well as being directly related to less individual reports of bullying itself. Such findings indicate that conflict management climate buffers the risk psychosocial stressors pose for the onset of a bullying process. In a cross-sectional study with a moderated-mediation design, Einarsen and colleagues (2018) showed that such a climate not only moderated the relationship between exposure to bullying and lowered job engagement, it was also related to less reports of exposure to bullying itself. Yet, only prospective studies may shed light on the possible role such a climate has when it comes to early intervention and prevention of a further escalating process.

Conflict management climate (CMC) can be understood as employees' perception of the extent to which interpersonal conflicts are handled well and fairly in the organisation (Rivlin, 2001). In a work environment with a strong CMC, employees experience that the organisation has proper and 
effective conflict management procedures, fair methods of conflict management, efficient and fair leaders in this respect, and that employees and management work together to solve problems that may arise in the organisation (Rivlin, 2001). By having procedures and rules that are familiar to everyone in the organisation, the employee knows how conflicts will be dealt with, and are confident that they actually will be handled. Procedures are standardized and fair, as they are the same for everyone, which can provide predictability and perceived control (Rivlin, 2001). CMC can also make employees feel safe to voice any concern and to speak out early on when mistreatment and unfairness takes place, as there is an expectation that negative acts will be addressed, and thus prevented and stopped (Zahlquist et al., 2019). Hence, CMC is not about the individuals own conflict management style or one's own ability to handle and cope with interpersonal conflicts, but rather one's trust in the organisation and its managers will and ability to intervene in and manage these conflicts if necessary.

A study among HR managers and elected health and safety representatives of Norwegian employees showed that such a climate was strongly related how well bullying cases were seen to be handled in the organisation (Einarsen, et al., 2017). Hence, a strong CMC can probably prevent bullying from further developing in the first place, as firm conflict management will weaken the relationship between precursors in the work environment (such as high demands and interpersonal frustration) and bullying (Zahlquist et al., 2019). A weak CMC, on the other hand, can create insecurity in the relationships between the members of the organisation, which may further threaten the psychological safety in the group, prompting new cases of bullying. Organisations with a weak CMC may both implicitly allow negative acts to continue, as the organisation does not address the underlying conflict or stressors, nor the bullying itself. Hence, a weak CMC can foster an environment that allows negative acts to evolve, as interpersonal tension and problems are not addressed, as well as implicitly allowing the very bullying situation itself to exist and escalate.

In empirical terms, there is ample general evidence that a poor social climate and leadership is involved as antecedents of bullying, even when one looks at observed workplace bullying (Agervold, 2009; Skogstad et al., 2011). Furthermore, research on the related concept of psychosocial safety climate has shown that such a perceived climate predicts a reduced prevalence of workplace bullying 4 years later (Dollard et al., 2017). The concept of psychosocial safety climate (PSC) focuses on the importance of employees' perception and appraisal of the organisations practice and procedure protecting the psychological health and safety of its employees (Dollard \& Bakker, 2010), where open communication and trust are seen as essential for maintaining a strong PSC (Bond et al., 2010). In an environment where the employees' health and safety are emphasized, it is natural to also prevent bullying early on. Even though a range of studies have documented the importance of such a climate in relation to workplace bullying (Dollard et al., 2017), it is still unknown exactly how such a climate works. CMC may be the actual ingredient and an important subfactor of PSC. Compared to PSC, CMC is a more specific factor related to conflict management, and especially pertinent to investigate in relation to bullying behaviour.

At present there is a lack of empirical evidence on how to prevent and manage workplace bullying (Einarsen \& Einarsen, 2021). Hence, we need more knowledge of the mechanism involved in workplace bullying to inform further prevention strategies. Therefore, using questionnaire data collected with a time lag of 1 year, we investigated the possible moderating effect of CMC in the developmental process of bullying over time. We expected that CMC moderates the relationship between exposure to bullying behaviour at a given time and the degree of bullying behaviour reported 1 year later (see Fig. 1). The following hypothesis was tested:

H1: Conflict management climate moderates the relationship between exposure to bullying behaviour at base line and subsequent exposure 1 year later so that the association between exposure at the two time points is weaker for targets perceiving a strong climate for conflict management and stronger for participants reporting a poor climate for conflict management.

\section{Methods}

\section{Design and Procedure}

The present prospective study was based on data from a representative and nationwide survey in the Norwegian workforce. Data was gathered by Statistics Norway (SSB), who drew a random sample of 3500 respondents from the official Norwegian employee-register. Respondents represent most kinds of organizations and industries throughout the country, like education, administration, managers, legal positions, research, health sector, architecture and geology, economics and banking, consultants, various professions such as electricians and carpenters, emergency services, shop and sales, transport, ICT, real estate, engineers, public sector employees including municipalities, and food and customer service. The survey was approved by the Regional Committee of Medical Research Ethics in the East of Norway (REK 
Fig. 1 Theoretical model of conflict management climate as a moderator in the process of bullying

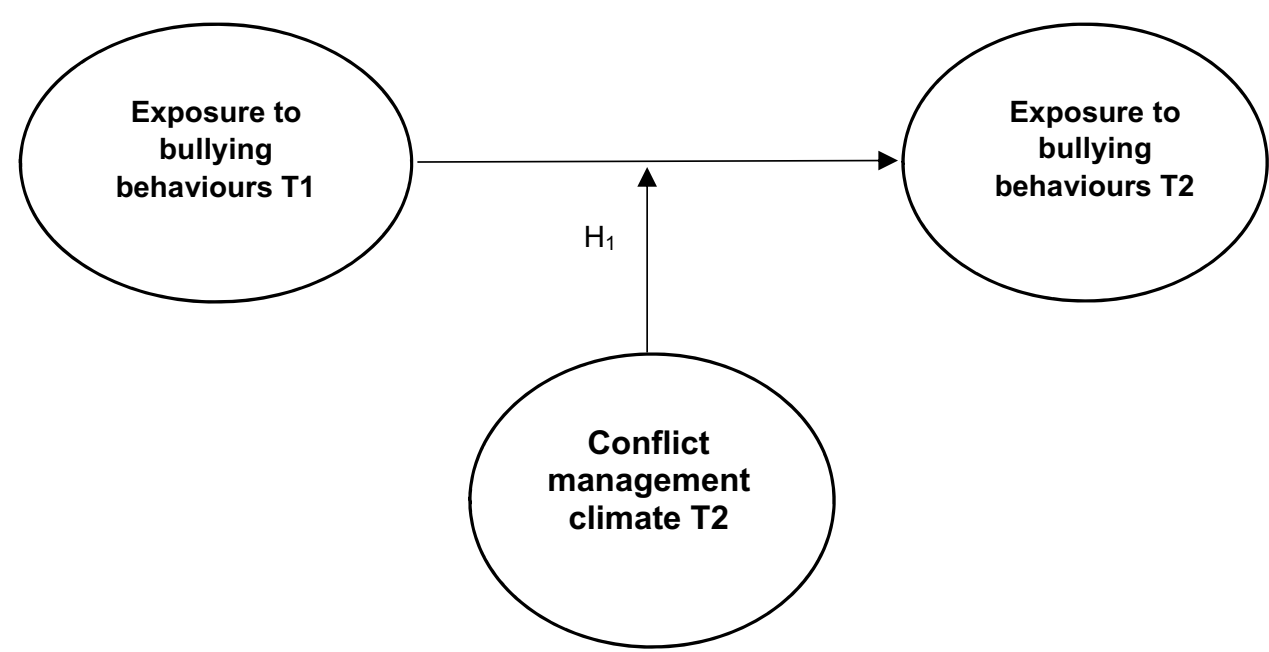

2014/ 1725). Criteria for inclusion was being registered as an employee in a Norwegian company, aged 18-61 years.

\section{Sample}

The first round of questionnaires was sent out via e-mail in the spring of 2015, with a total of 1459 responses (response rate $32 \%$ ) at baseline (T1). All who attended at baseline was invited to a follow up study (T2) in the spring of 2016. A total of 1197 participated at T2, providing a longitudinal sample with a response rate above $80 \%$. At baseline, the average age was 45.20 years $(\mathrm{SD}=9.98)$, and the sample consisted of $52.1 \%$ women and $47.9 \%$ men. Of all respondents, $90.1 \%$ were full-time employees, and $34.7 \%$ had a managerial or supervisor role. Hence, respondents with a manager and leadership role are over-represented in the sample. Cronbach's alpha values, means, standard deviations (SD), and correlations for study variables are presented in Table 1.

\section{Instruments}

The short version of the Negative Acts Questionnaire (NAQS; Notelaers et al., 2019) was used to measure exposure to workplace bullying behaviour. The inventory includes nine items describing different negative acts which can be perceived as bulling if happening regularly over some time, yet without labelling them as bullying per se. The questions distinguished between direct negative acts: have you experienced being shouted at or being a target of spontaneous outbursts of rage?, and indirect negative acts: have you experienced social exclusion at work?, as well as addressing acts of a work-related and a person-related nature. The responses were given on a 5-point scale from 1 to 5 (never, occasionally, monthly, weekly, daily). Internal consistency of the NAQ-S in the present study as measured with Cronbach's alpha was 0.86 at $\mathrm{T} 1$ and 0.87 at $\mathrm{T} 2$, respectively, and well above the often set cut-off at 0.70 (DeVellis, 2012).

Conflict management climate (CMC) was measured with four items from the Conflict Management Climate Scale (Einarsen et al., 2018; Rivlin, 2001; Zahlquist et al., 2019): (1) If I have a serious disagreement with someone at work, I know who I should talk to about it. (2) The way we deal with disagreements between employees in my unit works well. (3) My superiors deal with conflicts in a good manner. (4) We have good procedures and methods for raising disagreements and conflicts in my workplace. Response options were given on a Likert scale from 1 (disagree) to 5 (strongly agree). Thus, a high score would be an indicator of a perceived strong conflict management climate. CMC was measured at T2. The internal consistency was 0.88 as estimated with Cronbach's alpha, far above acceptable limits.

Time is decisive in the bullying process, and we reasoned that a time lag of 1 year was necessary in order for a bullying case to evolve and escalate, and simultaneously long enough for employees to evaluate and assess the general perceived conflict management climate in the same period. In the present study, any changes of perceived CMC over time are not relevant, as we investigate how changes in exposure to bullying behaviours may depend on the perceived CMC. Hence, this is a study of a factor (CMC) that may halt and prevent the escalation process involved in bullying over time. As our measures have a retrospective focus, that is describing what has been, we included CMC at T2 as this would be a measure of how the perceived climate has actually been in the period we are looking at. Measuring CMC at T1 would have been a measure of the climate before the period we are studying. As age and gender is related to the experience of bullying behaviour (Rivers \& Smith, 1994) with women being over-represented among victims (Zapf et al., 2020) and 
Table 1 Cronbach's alpha values, means, standard deviations (SD), and correlations (Pearson's r) for the study's variables

\begin{tabular}{|c|c|c|c|c|c|c|c|c|}
\hline Variables & $\alpha$ & Mean & SD & 1 & 2 & 3 & 4 & 5 \\
\hline 1. Age & & 45.20 & 9.98 & - & & & & \\
\hline 2. Gender & & 1.52 & 0.50 & $-.09 * *$ & - & & & \\
\hline 3. Leadership status & & 1.65 & 0.48 & $-.07 * *$ & $.19 * *$ & - & & \\
\hline 4. Bullying behaviour $\mathrm{T} 1$ & .86 & 1.19 & 0.34 & -.03 & -.00 & -.03 & - & \\
\hline 5. Conflict management climate $\mathrm{T} 2$ & .88 & 3.70 & 1.00 & $.10^{* *}$ & -.01 & $-.10^{* *}$ & $-.37 * *$ & - \\
\hline 6. Bullying behaviour T2 & .87 & 1.18 & 0.33 & -.03 & -.02 & -.02 & $.63 * *$ & $-.43 * *$ \\
\hline
\end{tabular}

** Correlations are significant at the 0.01 level (2-tailed)

subordinates more at risk of being bullied than are leaders/managers (Rayner et al., 2002), both age, gender and leadership status were included as control variables.

\section{Data Analysis}

IBM SPSS Statistics (version 25.0) was used to analyse scale reliability $(\alpha)$, demographics, and correlations between included variables. A confirmatory factor analysis (CFA) and a structural equation modelling (SEM) in Mplus 7. 4 (Muthén \& Muthén, 2012) were used to test the construct validity of the included scales, and to test the hypothesized moderated relationship between perceived climate for conflict management and bullying behaviour, respectively (see Klein \& Moosbrugger, 2000; Muthen \& Asparouhov, 2003). The independent variable (bullying behaviour at baseline), the moderator (perceived climate for conflict management), and the dependent variable (bullying behaviour one year later) were individual-level variables. Root-mean-square error of approximation (RMSEA), Tucker-Lewis Index (TLI), and comparative fit index (CFI) were used fit indices. Values close to 0.08 for RMSEA indicate a satisfactory fit between measurement model and observed data, while for TLI and CFI, values above 0.95 indicates good fit (Browne \& Cudeck, 1993). The significance level was set to $p<0.05$.

\section{Results}

The results from the CFA in Mplus supported the constructed validity of a 3-factor model, including exposure to workplace bullying at $\mathrm{T} 1$, conflict management climate at $\mathrm{T} 2$, and exposure to workplace bullying at $\mathrm{T} 2$ (see Table 2). Three models were tested and compared (see Table 3 ). The inspection of the fit indices supported the 3 -factor model $(\mathrm{RMSEA}=0.03, \mathrm{TLI}=0.98, \mathrm{CFI}=0.98)$.

Cronbach's alpha values, means, standard deviations (SD), and correlations for study variables are presented in Table 1. Gender was not correlated to variables of interest and was therefore excluded from further analyses. SEM in Mplus was used to test the relationship between exposure to bullying behaviours and conflict management climate. Firstly, the direct effect model was tested with bullying behaviour at $\mathrm{T} 1$ $(\beta=0.66, p=0.000)$ and conflict management climate at $\mathrm{T} 2$ $(\beta=-0.28, p=0.000)$ as predictors of bullying exposure at T2. The full model explained $67 \%$ of the variance in exposure to bullying behaviour at $\mathrm{T} 2$, and fit indices (Table 4) indicated that the model had satisfactory fit to the data $\left[\chi^{2}(206, N=879)=510.11, p=0.000, \mathrm{CFI}=0.98, \mathrm{TLI}=0.98\right.$, RMSEA $=0.04]$. Age and leadership status were included as control variables at first; however, as they did not have significant relationships to the outcome, and the other estimates did not change significantly, the control variables were excluded from the analysis (see Becker et al., 2016).

Then an interaction model was tested (see Figs. 2 and 3), where workplace bullying at T1 $(\beta=0.41, p=0.000)$, conflict management climate T2 $(\beta=-0.31, p=0.000)$, and the product term (workplace bullying behaviour at $\mathrm{T} 1 *$ conflict management climate $\mathrm{T} 2: \beta=-0.33, p=0.000$ ) were all related to workplace bullying behaviour at $\mathrm{T} 2$. The full model explained $47 \%$ of the variance in exposure to bullying behaviours at $\mathrm{T} 2$. The interaction was only significant under conditions of a weak conflict management climate $(b=0.23, p=0.000)$, indicating that a strong conflict management climate at $\mathrm{T} 2$ entirely buffers the relationship between workplace bullying at $\mathrm{T} 1$ and $\mathrm{T} 2(b=0.02, p=0.484)$, supporting the study's hypothesis.

\section{Discussion}

The present study was designed to study the role of perceived climate for conflict management with regard to the potential escalation of workplace bullying over time. In line with our hypothesis, the results showed that the experience of a strong conflict management climate acted as a buffer in the relationship between the bullying behaviour at baseline and subsequent exposure to bullying behaviour one year later. Hence, reporting a strong conflict management climate reduces the risk of reporting increased exposure to bullying behaviour over time, in our case a year later. A basic tenet of early theorizing holds that bullying behaviour 
Table 2 Items and standardized factor loadings for the included variables

\begin{tabular}{|c|c|c|c|}
\hline $\begin{array}{l}\text { Items } \\
\text { NAQ T1 }\end{array}$ & \multicolumn{3}{|c|}{ Factor loadings } \\
\hline Someone withholding information which affects your performance & .69 & & \\
\hline Spreading of gossip and rumours about you & .80 & & \\
\hline Being ignored or excluded & .81 & & \\
\hline Having insulting or offensive remarks made about your person, attitudes or your private life & .80 & & \\
\hline Being shouted at or being a target of spontaneous rage & .64 & & \\
\hline Repeated reminders of your errors or mistakes & .79 & & \\
\hline Being ignored or facing a hostile reaction when you approach & .81 & & \\
\hline Persistent criticism of your work and effort & .83 & & \\
\hline Practical jokes carried out by people you do not get along with & .81 & & \\
\hline \multicolumn{4}{|l|}{ NAQ T2 } \\
\hline Someone withholding information which affects your performance & & .70 & \\
\hline Spreading of gossip and rumours about you & & .87 & \\
\hline Being ignored or excluded & & .84 & \\
\hline Having insulting or offensive remarks made about your person, attitudes or your private life & & .87 & \\
\hline Being shouted at or being a target of spontaneous rage & & .65 & \\
\hline Repeated reminders of your errors or mistakes & & .78 & \\
\hline Being ignored or facing a hostile reaction when you approach & & .84 & \\
\hline Persistent criticism of your work and effort & & .87 & \\
\hline Practical jokes carried out by people you do not get along with & & .76 & \\
\hline \multicolumn{4}{|l|}{ Conflict management climate $\mathrm{T} 2$} \\
\hline If I have a serious disagreement with someone at work, I know who I should talk to about it & & & .67 \\
\hline The way we deal with disagreements between employees in my unit works well & & & .90 \\
\hline My superiors deal with conflicts in a good manner & & & .95 \\
\hline We have proper procedures and methods for raising disagreements and conflicts in my workplace & & & .90 \\
\hline
\end{tabular}

will evolve out of interpersonal conflicts and become ever more aggressive and escalated if the situation is not intervened or otherwise stopped (Björkvist, 1992). Our findings showed that perceived strong climate for conflict management neutralized the escalation of workplace bullying over time.

Bullying often arises as an "end point" triggered by escalating interpersonal conflicts (Baillien et al., 2017; Leymann, 1992, 1996; Notelaers et al., 2018). Addressing conflicts and negative acts in early stages has been proposed to be of great importance in order to end the escalation of the bullying process (Leymann, 1992, 1996), in line with the present findings. Addressing task/related or person-related conflicts in the workplace inhibit the intention to leave, and more importantly, it seems to have a positive effect on resolving the conflict (Van Gramberg et al., 2019). To speak up about a conflict or bullying situation is probably easier in a context of a strong CMC, where the organisation has well known and fair procedures and a habit for dealing effectively with conflicts (Rivlin, 2001). When not knowing or trusting how interpersonal problems are handled, or even if problems will be handled at all, employees will be less likely to "talk out loud" about matters involving conflicts and bullying behaviour, hence facilitating further escalation of existing

Table 3 Fit statistics for confirmatory factor analyses

\begin{tabular}{lllllll}
\hline Model & Latent factors & $\chi^{2}$ & Df & CFI & TLI & RMSEA \\
\hline 1 Factor model & WBT1, WBT2, CMCT2 & $2769.16^{*}$ & 209 & .87 & .85 & .09 \\
2 Factor model & WBT1 and T2+CMCT2 & $779.51^{*}$ & 208 & .97 & .97 & .04 \\
3 Factor model & WBT1 + WBT2 + CMCT2 & $\mathbf{5 3 9 . 8 2 *}$ & $\mathbf{2 0 6}$ & $\mathbf{. 9}$ & $\mathbf{. 9 8}$ & $\mathbf{. 0 3}$ \\
\hline
\end{tabular}

Measurement model is presented in bold

$W B$ workplace bullying, $C M C$ conflict management climate, $T 1$ baseline, $T 2$ 1-year time lag 
Table 4 Fit statistics for the hypothesised relationships

\begin{tabular}{llllllll}
\hline Model & Latent factors & $\chi^{2}$ & Df & CFI & TLI & RMSEA & $\mathrm{R}^{2}$ \\
\hline Main model & WBT1, CMCT2, WBT2 & $510.11^{*}$ & \multirow{2}{*}{206} & .98 & .98 & .04 & .67 \\
Interaction model & WBT1, CMCT2, & & & & & & .47 \\
& WBT1*CMCT2, WBT2 & & & & & & \\
\hline
\end{tabular}

Listwise deletion of missing data is applied in both models $(N=879)$

$W B$ workplace bullying, $C M C$ conflict management climate, $T 1$ baseline, $T 21$-year time lag interpersonal problems. Bullying behaviours that exists in an environment with a weak CMC could therefore more easily trigger more bullying and new cases, fostering further harm towards both existing targets and new targets.

Managers motivated, competent, and committed to intervene in conflicts prevent mere interpersonal conflicts from escalating into bullying behaviour (Rivlin, 2001). Managers who are able to resolve conflicts effectively are suggested to make a big difference as to whether or not employees experience bullying or not (Baillien et al., 2009; O'Moore et al., 1998), indicating the important role of managers in stopping conflict escalation. This directs the attention to leadership, which seem to be particularly relevant in the relation to the escalation of bullying over time (Ågotnes et al., 2018; Blomberg \& Rosander, 2019; Nielsen et al., 2020). Bullying allowed to continue because it is tolerated, directly or indirectly, through lack of management intervention, may lead to an escalation in aggressive behaviour (Brodsky, 1976). This corresponds with cross-sectional evidence indicating that a weak conflict management climate increases the negative outcomes associated with bullying as well as being related to less reported exposure to bullying behaviours (Einarsen et al., 2018; Naseem \& Ahmed, 2020).

Our results support the idea that a strong CMC can act as a tool to stop this development, thus preventing escalation of bullying behaviours and the negative consequences that follows. The results of the present study are supported by other studies showing that conflict management climate (Zahlquist et al., 2019) and psychosocial safety climate (Dollard et al., 2017) prevented bullying from developing. In our study, we found that weak CMC strengthens the relationship between bullying behaviour at the two different times, which can be seen in the context of Zahlquist and colleagues (2019), who showed that a strong CMC has a buffering effect on the relationship between work stressors and reports of bullying. However, Zahlquist and colleagues' (2019) study was a cross-sectional, yet multi-level, design. An important contribution of the present study is its prospective design.
Fig. 2 Results from the moderation analysis of with latent factor interaction (standardized beta coefficients) $(N=879)$

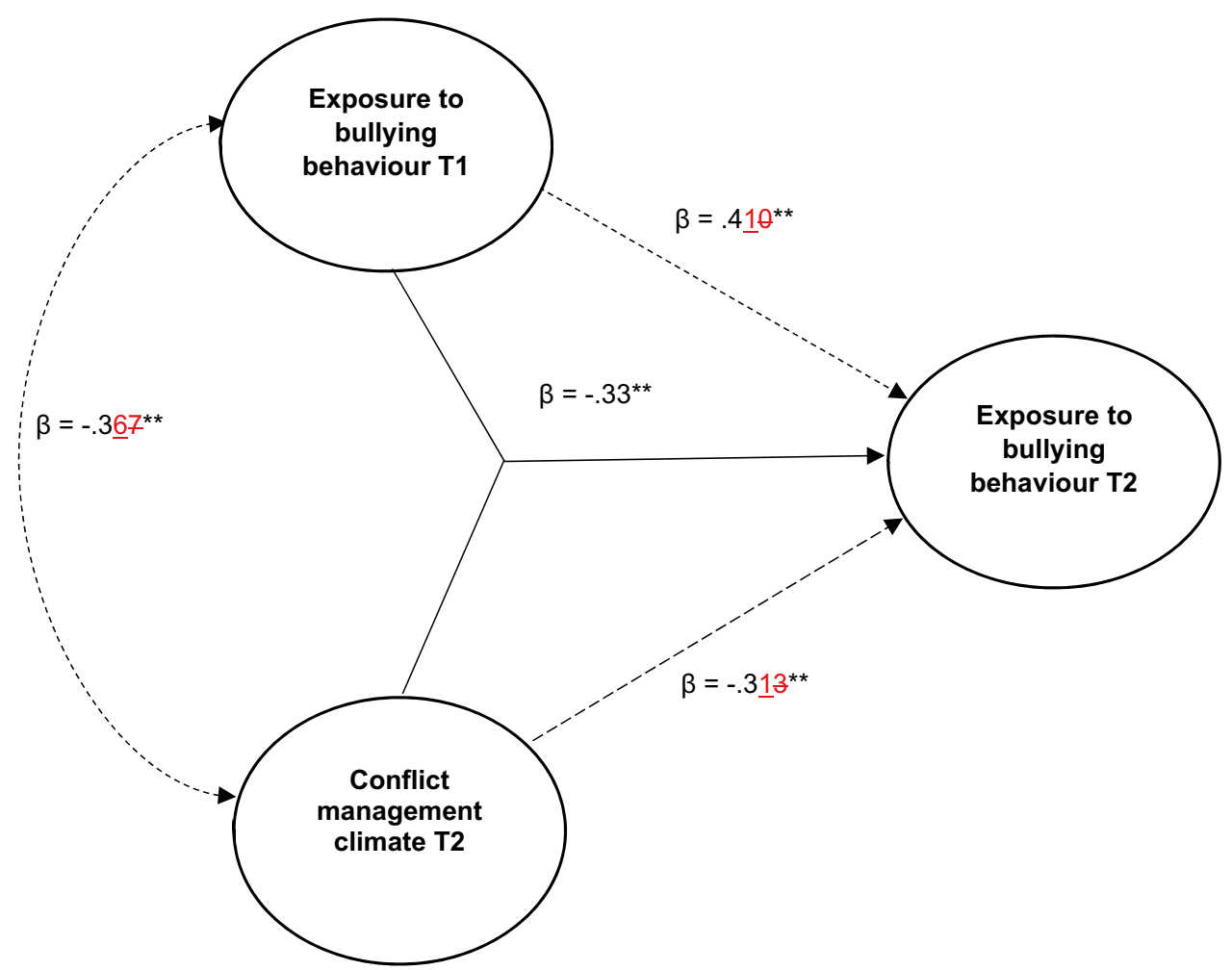


Fig. 3 The interaction effect of exposure to bullying behaviours and conflict management climate on later exposure to bullying behaviours. Low $=1 \mathrm{SD}$ below the mean. High $=1 \mathrm{SD}$ above the mean. WB workplace bullying, CMC conflict management climate

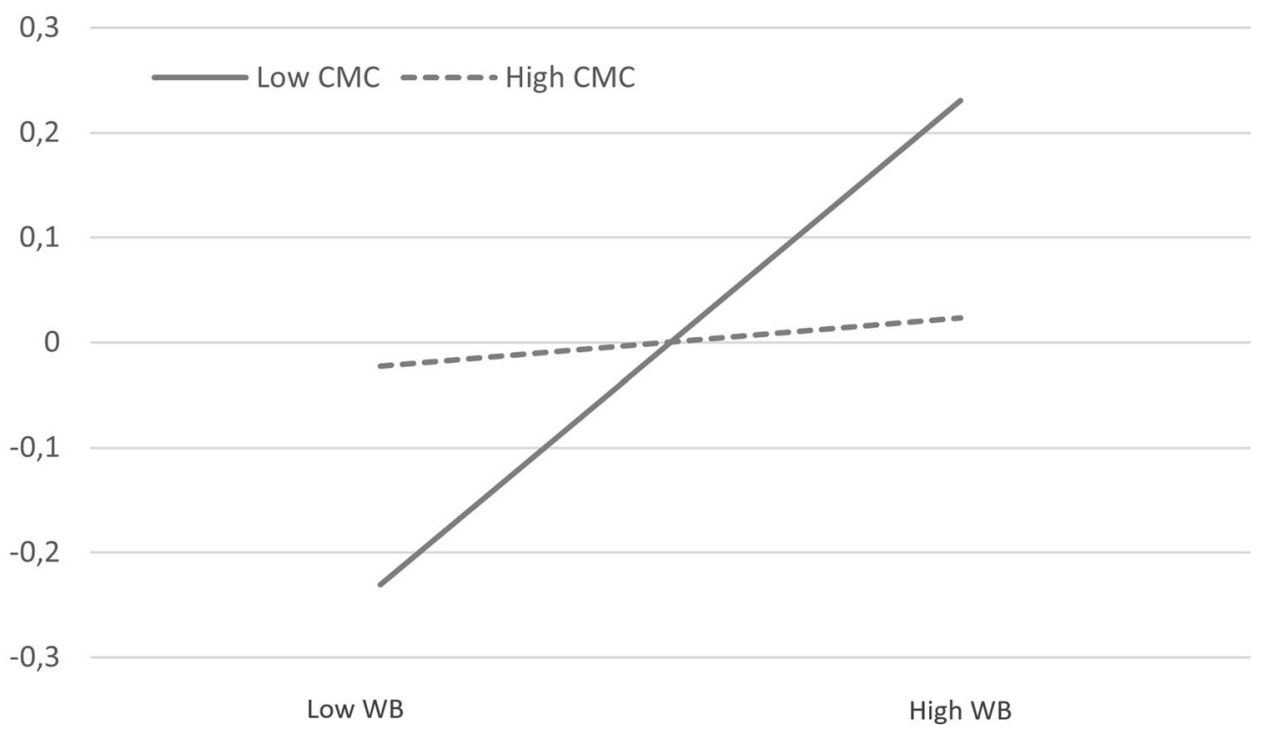

The discovery that CMC entirely buffers the development of workplace bullying 1 year later on fills an important gap in the existing literature. It has long been speculated on the importance of conflict management in the bullying process (Baillien et al., 2009; Leymann, 1996). Revisiting this long-held hypothesis, we illustrated that it is possible to prevent the escalation of new and existing bullying cases by creating a social environment where employees perceive and trust that interpersonal problems are firmly and fairly managed. Further, our findings showed that pre-existing exposure to bullying behaviour largely explain further escalation of existing and new cases of bullying behaviours when the social climate does not hold such qualities. In summary, this indicates that conflict management climate is a noticeable resource which can neutralize the development of workplace bullying.

\section{Methodological Limitations}

There are some limitations in the present study that need to be mentioned. The response rate at the first measurement time was low (32\%), although the respondents who had responded initially also responded to the follow-up survey to a greater extent $(80 \%)$. The analysis used self-reported data, and therefore, there may be some specific bias associated with this. When data is collected from only one source and with only one method, the data material can be influenced by, among other things, social desirability, the "halo effect," recall accuracy, and common method variance (Podsakoff \& Organ, 1986). In sum, these response trends may reduce the internal validity of the data. At the same time, it is impossible to eliminate all biases when using self-reported data. Furthermore, the experience of being bullied is to some extent a subjective one as is the perception of one's social climate. The use of items describing observable behaviours should however reduce these biases somewhat. Our use of longitudinal data should also reduce these effects somewhat.

Conflict management climates can be explored both as an individual perception as in the present study (see also Einarsen et al., 2018) and as a collective experience of a group level climate, as in the study by Zahlquist and colleagues (2019). On may argue that to understand the bullying phenomenon, studies that acknowledge the personal experience are recommended (Parzefall \& Salin, 2010). Yet, Zahlquist and colleagues (2019) have shown that such a climate may also exist on a team level and may not merely be a subjective perception by an individual target. However, being exposed to bullying can potentially affect a person's perception of the CMC, which in turn can affect the responses in the survey, a possibility we unfortunately could not test in the present data as CMC was only measured at $\mathrm{T} 2$ in the present study.

\section{Conclusions and Implications for Future Research}

The findings of the present study is noteworthy knowledge for both employers, managers, worker representatives, and management consultants alike, as they show that bullying may be prevented by establishing and maintaining a strong climate for conflict management. Such a climate appears to be a noticeable resource in organisations which may prevent, halt, or neutralize the escalation and development of perceived exposure to bullying. Specifically, while weak conflict management climates seem to amplify the risk of increased exposure to bullying behaviour over time, working in an organisation with a strong climate for conflict 
management, on the other hand, have the opposite effect and prevents the escalation of workplace bullying. From our study, it therefore seems possible to create a bullyproof environment by focusing on a contextual factor highly under control of upper and middle management. Measures to achieve such a climate would have to include as a minimum information and awareness raising among managers, the development of proper and fair conflict management procedures, and training in conflict management skills in line with these written procedures for managers and HR personnel (see also Hoel \& Einarsen, 2020; Einarsen \& Einarsen, 2021). Furthermore, information on these procedures needs to be given to employees along with assurances that the organisation will indeed be trustworthy, fair, and consistent in such situations. Developing these procedures in collaboration with health and safety personnel and in particular employee representatives will most likely also be beneficial. Yet, at the end of the day, it will be the quality of and the actual use of these procedures by mangers that will be the most effective factor in creating and shaping such a climate. Hence, the organisation and its managers need to prove its commitment to these procedures over time.

Acknowledgements We would like to thank Øystein Løvik Hoprekstad for his support on the statistical analyses.

Funding Open access funding provided by University of Bergen (incl Haukeland University Hospital). This paper is supported by the Norwegian Research Council—NFR (grant number 237777/250127).

Data Availability Dataset used in this study is available, for request contact corresponding authors. Any inquiries regarding the dataset can be addressed to Morten Birkeland Nielsen (morten.nielsen@stami.no)

\section{Declarations}

Ethics Approval The study was performed in line with the principles of the Declaration of Helsinki. The survey was approved by the Regional Committee of Medical Research Ethics in the East of Norway (REK 2014/1725).

Conflict of Interest The authors declare no competing interests.

Open Access This article is licensed under a Creative Commons Attribution 4.0 International License, which permits use, sharing, adaptation, distribution and reproduction in any medium or format, as long as you give appropriate credit to the original author(s) and the source, provide a link to the Creative Commons licence, and indicate if changes were made. The images or other third party material in this article are included in the article's Creative Commons licence, unless indicated otherwise in a credit line to the material. If material is not included in the article's Creative Commons licence and your intended use is not permitted by statutory regulation or exceeds the permitted use, you will need to obtain permission directly from the copyright holder. To view a copy of this licence, visit http://creativecommons.org/licenses/by/4.0/.

\section{References}

Agervold, M. (2009). The significance of organizational factors for the incidence of bullying. Scandinavian Journal of Psychology, 50(3), 267-276.

Ågotnes, K. W., Einarsen, S. V., Hetland, J., \& Skogstad, A. (2018). The moderating effect of laissez-faire leadership on the relationship between co-worker conflicts and new cases of workplace bullying: A true prospective design. Human Resource Management Journal, 28(4), 555-568.

Baillien, E., Escartín, J., Gross, C., \& Zapf, D. (2017). Towards a conceptual and empirical differentiation between workplace bullying and interpersonal conflict. European Journal of Work and Organizational Psychology, 26(6), 870-881. https://doi.org/10. 1080/1359432X.2017.1385601

Baillien, E., Neyens, I., De Witte, H., \& De Cuyper, N. (2009). A qualitative study on the development of workplace bullying: Towards a three way model. Journal of Community and Applied Social Psychology, 19(1), 1-16.

Berthelsen, M., Skogstad, A., Lau, A., \& Einarsen, S. (2011). Do they stay or do they go? A longitudinal study of intentions to leave and exclusion from working life among targets of workplace bullying. International Journal of Manpower, 32, 178-193. https://doi.org/ 10.1108/01437721111130198

Becker, T. E., Atinc, G., Breaugh, J. A., Carlson, K. D., Edwards, J. R., \& Spector, P. E. (2016). Statistical control in correlational studies: 10 essential recommendations for organizationa researchers. Journal of Organizational Behavior, 37 (2); 157-167,

Björkvist, K. (1992). Harassment exists among employees at Abo Academy. Meddelande Fran Abo Akademi, 9, 14-17.

Blomberg, S., \& Rosander, M. (2019). Exposure to bullying behaviours and support from co-workers and supervisors: A three-way interaction and the effect on health and well-being. International Archives of Occupational and Environmental Health, 1-12.

Bond, S. A., Tuckey, M. R., \& Dollard, M. F. (2010). Psychosocial safety climate, workplace bullying, and symptoms of posttraumatic stress. Organization Development Journal, 28, 37-56.

Brodsky, C. M. (1976). The harassed worker. Toronto: Lexington Books: DC: Heath \& Co.

Browne, M. W., \& Cudeck, R. (1993). Alternative ways of assessing model fit. In K. A. Bollen \& J. S. Long (Eds.), Testing structural equation models (pp. 136-62). Newbury Park, CA: SAGE.

DeVellis, R. F. (2012). Scale developement: Theory and applications (3rd ed.). SAGE.

Dollard, M. F., \& Bakker, A. B. (2010). Psychosocial safety climate as a precursor to conducive work environments, psychological heatlh problems, and employee engagement. Journal of Occupational and Organizational Psychology, 83, 579-599. https://doi.org/10. 1348/096317909X470690

Dollard, M. F., Dormann, C., Tuckey, M. R., \& Escartín, J. (2017). Psychosocial safety climate (PSC) and enacted PSC for workplace bullying and psychological health problem reduction. European Journal of Work and Organizational Psychology, 26, 844-857. https://doi.org/10.1080/1359432x.2017.1380626

Einarsen, K. \& Einarsen, S.V. (2021). Combating workplace bullying: Interventions and the role of the organization's ethical infrastructure. In P.K. Smith \& J. O’Higgins Norman (Eds), The Wiley Blackwell Handbook of bullying: A comprehensive and International Review of Research and Interventions, Volume 1. Wiley Blackwell.

Einarsen, S., Hoel, H., Zapf, D., \& Cooper, C. (2020). The concept of bullying and harassment at work. In S. Einarsen, H. Hoel, D. Zapf, \& C. Cooper (Eds.), Bullying and harassment in the workplace developments in theory, research, and practice (pp. 3-39). 
Einarsen, K., Mykletun, R. J., Einarsen, S. V., Skogstad, A., \& Salin, D. (2017). Ethical infrastructure and successful handling of workplace bullying. Nordic Journal of Working Life Studies, 7(1), 37-54.

Einarsen, S., \& Skogstad, A. (1996). Prevalence and risk groups of bullying and harrassment at work. European Journal of Work and Organizational Psychology, 5(2), 185-202.

Einarsen, S., Skogstad, A., Rørvik, E., Lande, Å. B., \& Nielsen, M. B. (2018). Climate for conflict management, exposure to workplace bullying and work engagement: A moderated mediation analysis. International Journal of Human Resource Management, 29, 549-570. https://doi.org/10.1080/09585192.2016.1164216

Glambek, M., Skogstad, A., \& Einarsen, S. (2014). Take it or leave: A five-year prospective study of workplace bullying and indicators of expulsion in working life. Industrial Health, 53, 160-170.

Hauge, L. J., Skogstad, A., \& Einarsen, S. (2007). Relationships between stressful work environments and bullying: Results of a large representative study. Work \& Stress, 21(3), 220-242.

Hoel, H., \& Einarsen, S. (2020). Investigating complaints of bullying and harassment. In S. Einarsen, H. Hoel, D. Zapf, \& C. Cooper (Eds.), Bullying and harassment in the workplace: Developments in theory, research, and practice (pp.541-562).

Keashly, L., Minkowitz, H., \& Nowell, B. L. (2020) Conflict, Conflict Resolution and Workplace Bullying. In S. Einarsen, H. Hoel, D. Zapf, \& C. Cooper (Eds.), Bullying and harassment in the workplace developments in theory, Research, and Practice (pp. 331-362).

Klein, A., \& Moosbrugger, H. (2000). Maximum likelihood estimation of latent interaction effects with the LMS method. Psychometrika, 65(4), 457-474.

Leymann, H. (1990). Mobbing and psychological terror at workplaces. Violence and Victims, 5(2), 119-126.

Leymann, H. (1992). Från mobbning til utslagning $i$ arbetslivet (From bullying to expulsion in working life). Publica.

Leymann, H. (1996). The content and development of mobbing at work. European Journal of Work and Organizational Psychology, 5, 165184. https://doi.org/10.1080/13594329608414853

Muthén, B., \& Asparouhov, T. (2003). Modeling interactions between latent and observed continuous variables using maximum-likelihood estimation in Mplus. Mplus Web Notes, 6(1), 1-9.

Muthén, L. K., \& Muthén, B. O. (2012). Mplus user's guide (7th ed.). Los Angeles, CA: Muthén \& Muthén.

Naseem, K., \& Ahmed, A. (2020). Presenteeism as a consequence of workplace bullying: Mediating role of emotional exhaustion and moderation of climate for conflict management. Pakistan Journal of Commerce and Social Sciences (PJCSS), 14(1), 143-166.

Nielsen, M. B., Christensen, J. O., Finne, L. B., \& Knardahl, S. (2020). Workplace bullying, mental distress, and sickness absence: The protective role of social support. International Archives of Occupational and Environmental Health, 93(1), 43-53.

Nielsen, M. B., \& Einarsen, S. (2012). Outcomes of exposure to workplace bullying: A meta-analytic review. Work \& Stress, 26, 309-332. https://doi.org/10.1080/02678373.2012.734709

Notelaers, G., Van der Heijden, B., Guenter, H., Nielsen, M. B., \& Einarsen, S. V. (2018). Do interpersonal conflict, aggression and bullying at the workplace overlap? A latent class modeling approach. Frontiers in Psychology, 9, 1743.

Notelaers, G., Van der Heijden, B., Hoel, H., \& Einarsen, S. (2019). Measuring bullying at work with the short-negative acts questionnaire: Identification of targets and criterion validity. Work \& Stress, 33(1), 58-75.

Olweus, D. (1993). Bullying at schools: What we know and what we can do. Blackwell.
O’Moore, M., Seigne, E., McGuire, L., \& Smith, M. (1998). Victims of bullying at work in Ireland. Journal of Occupational Health and Safety - Australia and Zew Zealand, 14, 569-574.

Parzefall, M. R., \& Salin, D. M. (2010). Perceptions of and reactions to workplace bullying: A social exchange perspective. Human Relations, 63(6), 761-780.

Podsakoff, P. M., \& Organ, D. W. (1986). Self-reports in organizational research: Problems and prospects. Journal of Management, 12(4), 531-544.

Rayner, C., Hoel, H., \& Cooper, C. L. (2002). Bullying at work: What we know, who is to blame and what can we do. Taylor Francis.

Rivers, I., \& Smith, P. K. (1994). Types of bullying behaviour and their correlates. Aggressive Behavior, 20(5), 359-368.

Rivlin, J. N. (2001). Conflict management climate related to employment litigation. Atlanta: Georgia Institute of Technology.

Skogstad, A., Torsheim, T., Einarsen, S., \& Hauge, L. J. (2011). Testing the work environment hypothesis of bullying on a group level of analysis: Psychosocial factors as precursors of observed workplace bullying. Applied Psychology, 60(3), 475-495.

Stouten, J., Baillien, E., Van den Broeck, A., Camps, J., De Witte, H., \& Euwema, M. (2010). Discouraging bullying: The role of ethical leadership and its effects on the work environment. Journal of Business Ethics, 95(1), 17-27.

Törnroos, M., Salin, D., \& Hanson, L. M. (2020). High-involvement work practices and conflict management procedures as moderators of the workplace bullying-wellbeing relationship. Work \& Stress, 1-20.

Van Gramberg, B., Teicher, J., Bamber, G. J., \& Cooper, B. (2019). Employee voice, intention to quit, and conflict resolution: Evidence from Australia. ILR Review, 73(2), 393-410. https://doi. org/10.1177/0019793919876643

Zahlquist, L., Hetland, J., Skogstad, A., Bakker, A. B., \& Einarsen, S. V. (2019). Job demands as risk factors of exposure to bullying at work: The moderating role of team-level conflict management climate. Frontiers in Psychology, 10, 1-11.

Zapf, D., Escartin, J., Scheppa-Lahuani, M., Einarsen, S. V., Hoel, H., \& Vartia, M. (2020). Empirical findings on prevalence and risk groups of bullying in the workplace. Bullying and Harassment in the Workplace: Developments in Theory, Research, and Practice, 105.

Kristina Vaktskjold Hamre is a master's graduate in Work and Organisational Psychology from the University of Bergen, Norway. In her research she focuses on the consequences of bullying in the workplace, the dynamics of a bullying process, as well as highlighting factors that can reduce the development of bullying in the workplace.

Margrethe Ringen Fauske is a master's graduate in Work and Organisational Psychology from the University of Bergen, Norway. She is especially interested in investigating and identifying interventions that can prevent the development of, thus reduce the negative consequences associated with workplace bullying.

Iselin Reknes (PhD) is associate professor at the Department of Psychosocial Science at the University of Bergen, Norway. Iselin does research in Work and Organizational Psychology and is part of the Bergen Bullying Research Group. Her main research topics are workplace bullying, work environment stressors, personality, coping, and mental health. 
Morten Birkeland Nilsen (PhD) is research director at the National Institute of Occupational Health (STAMI) and Professor in Work and Organizational Psychology at the University of Bergen in Norway. His research interests include occupational health and well-being, workplace bullying, safety, and leadership. Nielsen is associate editor in Work \& Stress.

Johannes Gjerstad (PhD) is Lead Research Professor at the National Institute of Occupational Health (STAMI) and Professor of Physiology at the University of Bergen / University of Oslo, Norway. His research interests include stress-induced changes in the brain, the neuro-immune interface, genetics and subjective health complaints.

Ståle Valvatne Einarsen (PhD) is Professor in Work and Organisational Psychology at the University of Bergen, Norway, where he acts as Head of Bergen Bullying Research Group. He has published on issues related to workplace bullying, leadership, and creativity and innovation in organisations. In his research, he particularly focuses on workplace bullying and harassment, destructive leadership, and socialization to work. 